\title{
Considerations of Public and Private Entities on Tourism in the Romanian Coastal Area in the Context of Maritime Spatial Planning
}

\author{
Kamer-Ainur Aivaz ${ }^{1}$, Mari-Isabella Stan $^{2}$, Dragoș-Florian Vintilă $\breve{3}^{3}$ and Ionela Ionițiu ${ }^{4}$ \\ 1) 2) 3) 4) Ovidius University of Constanta, Constanta, Romania. \\ E-mail: aivaz_kamer@yahoo.com; E-mail: stanisabella@yahoo.com \\ E-mail:_vdragos@univ-ovidius.ro; E-mail: ionelaionitiu@yahoo.com

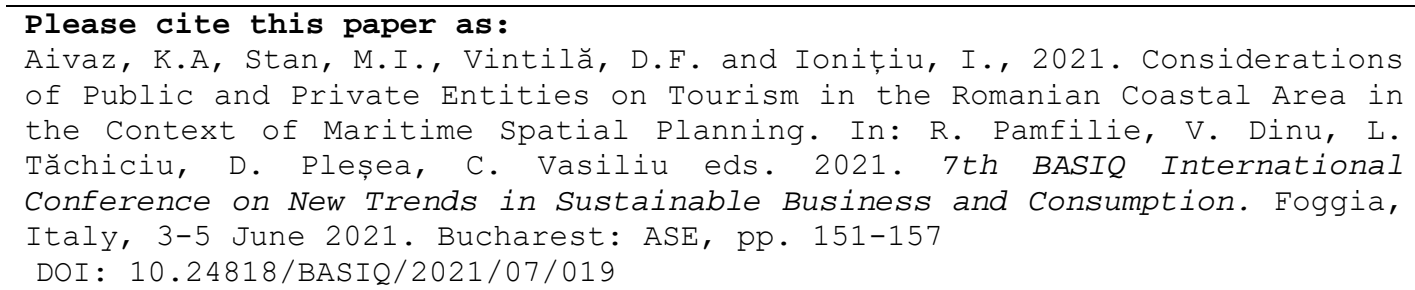

\begin{abstract}
Undoubtedly, given the extraordinary potential of the coastal area, insufficiently exploited so far, the field of tourist services must be included with priority in Romania's development strategies. In the context of the development of the Maritime Spatial Planning (MSP), the paper aims to provide signals on the quality of services in the tourism sector and their impact on the environment and related activities with the effort of the parties interested in coastal development. The research, based on a questionnaire addressed to stakeholders, grouped in public and private entities, uses descriptive, exploratory analysis methods and outlines several aspects regarding coastal tourism. The authors consider that these results should be extremely relevant for policymakers and stakeholders, especially as they are the ones who will bear the consequences of the land-sea interaction to promote sustainable tourism development in the context of maritime spatial planning. The most important stakeholder in our research comes from the public sector and is represented by the local public administration. It has the task of getting involved in the economic development of the coastal area, having at hand the multiple possibilities to manage this approach. The obtained results revealed a series of problems related to the quality of services, maintenance, and development of infrastructure and promotion, marketing, all these being recognized as "weaknesses" by most of the interviewed entities. The research results add value to the integrated and updated analysis of conflicts/synergies of maritime and environmental use, carried out within the MARSPLAN BS-II project in which the authors are involved.
\end{abstract}

Keywords: coastal tourism, Maritime Spatial Planning (MSP), stakeholders, environment. DOI: 10.24818/BASIQ/2021/07/019

\section{Introduction}

Maritime Spatial Planning (MSP) is considered in the broadest sense, as defined in the 2014/89/EU Directive, a public process by which authorities analyze and organize human activities in marine areas to achieve the environmental, economic, and social objectives. Sustainable planning of coastal and marine tourism needs support from several stakeholders to strike a balance between economic, environmental, and social issues (Wang, et al., 2016). Moreover, the European MSP Directive requires that land-sea interactions be taken into account to promote sustainable, integrated development and the management of human activities at sea. It is well known that maritime spatial planning (MSP) is one of the many framework conditions that shape development activities on land or at sea (SUPREME).

The coastal tourism activity that is carried out in this framework, has been enriched from year to year with new contents, has been diversified, knowing new forms: virtual tourism, soft tourism, shopping tourism, urban tourism, rural tourism, weekend tourism, adventure tourism, business tourism, cultural 
tourism, birdwatching, etc. The problems in which the tourism phenomenon can be approached have also diversified - it can be seen today, as we have shown, from several perspectives: marketing, management, globalization, integration in the European Union, liberalization of international trade in services, from an ethical point of view, of e-commerce, of the ability to generate profit under the conditions of elaborating appropriate tourist strategies, and so on.

Also, the dramatic reduction of transport time and costs, the simultaneous increase of travel comfort, the emergence of new tourist segments and new tourist destinations have introduced profound changes in the tourism sector. Competition between seaside destinations is taking place both nationally and internationally, and tourism companies are increasingly focusing on gaining significant competitive advantages over competitors. Rejuvenation strategies are therefore developed to gain or retain some market power over domestic or international competitors and, ultimately, to increase revenue. A crucial part of this complex, multifaceted strategy is the signaling of high quality of tourist services, through strong, credible, externally certified quality signals (Papagiorgiu, 2016).

In a time of concern about increasing profitability and environmental impact awareness, environmental certificates (eco-labels) are used to promote tourist destinations and increase their competitiveness. Although they are very visible in the media and we are witnessing the continuous growth of quality studies on environmental certifications, quantitative estimates of the economic impact are almost nonexistent. To fill this gap, this paper explores the particularities of Black Sea coastal tourism from the perspective of stakeholders as public and private entities focusing on issues related to elements of harmonization in the perspective of spatial maritime planning.

Over time, tourism development can generate jobs and financial income by providing recreational activities, education, and aesthetic pleasure to visitors, but it can also generate negative impacts on the environment (Donázar, Ceballos and Cortez-Avizanda, 2018). Environmental impacts refer to changes in the biological, physical, or chemical state of the environment that determine the quantity and quality of ecosystems and ultimately affect human health and socioeconomic performance (Hardy, Beeton and Pearson, 2002). Consequently, tourism can be a compromise and a controversial issue in protected areas. The approach to this compromise must comprehensively assess the benefits and costs of tourism. This requires integrated assessments that take into account environmental, socio-economic and cultural factors.

\section{Literature review}

Coastal tourism, along with all other forms of tourism, is an extraordinary driving force for economic growth, both at the national and zonal level, representing a significant alternative in employment and GDP creation (Sequeira and Nunes, 2008; Fayissa, Nsiah and Tadasse, 2008). Moreover, tourism initiatives promote the development of entrepreneurial activities either in less known, undeveloped areas or by groups of people who often do not participate in other large economic projects (Ashley and Mitchell, 2009). Among the various motivations for tourism, the pleasure of holidays and fun in coastal areas attract a lot of people. In recent years, public concern that these areas need to be used and managed sustainably has grown globally. Under these conditions, the issue of tourist impact on the environment should not be neglected at all. Although adequate legislative conditions have been created for the protection and use of the environment, there is an acute lack of approaches, both local, national, and international, regarding the tourist potential and implicitly in the dimension of the tourist impact on the environment (Hapenciuc, 2003).

Coastal tourism has often had an extremely negative impact on the environment. The approach was fragmentary and sometimes insufficient. However, changes in public opinion have forced policymakers to combine the use of coastal resources sustainably with the local development of the municipalities in which they are located (Holden, 2016; Hall, 2019).

In addition to the already known benefits of beaches and the sea, the introduction of elements aimed at adding value to stakeholders in their exploitation, they have made the issue of ecological development one of the strategies for increasing added value. Favoring environmental values (such as clean and certified beaches) stimulates a high-quality tourism sector, which targets a segment of the population 
that usually has a higher income, thus promoting the local economy and showing more respect for natural resources and location values (Liu, 2003; McKenna, Williams and Cooper, 2011; Capacci, Scorcu and Vici, 2015). In this respect, there is evidence that those hotels that had environmental certification were less affected (in terms of financial performance, for example) by the reduction in travel and tourism that some financial crises have generated (Cavero-Rubio and Amorós -Martínez, 2020).

\section{Methodology}

The research was conducted using descriptive and exploratory methods based on a questionnaire. The questionnaire, which was addressed to stakeholders grouped in public and private entities, outlined several aspects regarding coastal tourism. The analyzed sample consisted of 71 entities, 39 private entities, and 32 public entities. Data processing and obtaining the indicators used in the statistical description was performed using the Statistical Program for the Social Sciences (SPSS).

\section{Results and discussions}

To analyze the place and role of Black Sea tourism, we must consider the role played by the services sector, including tourism services in the economy of the area, as well as the impact of its development on related branches. An important number of factors must be taken into account when considering the choice of a tourist destination. The choice is to compare personal desires and needs with several tourist products from which one, which is supposed to be closest to the customer's needs, is selected. This is the reason why a clear distinction must be made between the elements of demand (the goals that the tourist wants to achieve during the holidays) and the elements of supply (variety and diversity of existing tourist products) (Hapenciuc, 2003).

The first aspect considered was to highlight the interaction of motivations-preferences, which aimed to satisfy the motivations that generated them in a preferred manner. From the multitude of answers, most of the interviewed entities stated that the main reason is rest, relaxation, recreation (40 entities). This type of tourism that includes relaxing activities is usually the one practiced annually, for a physical and intellectual relaxation, characterized by a lack of dynamism.

Another reason, mentioned by 15 entities, was the cultural one, which responds to the need for knowledge, acquisition of new knowledge, and development of human personality. It can manifest by participating in music festivals, art, visiting museums, and art galleries.

A number of 9 entities mentioned sports tourism by practicing various sports, characterized as a form of active participatory recreation. There were also some situations in which the entities mentioned the reasons: increasing revenues to the local budget, developing the company by attracting new customers, the desire to change the scenery, health care, the safety of navigation. Only two entities stated that tourism is not the subject of their institution or that coastal tourism is not of interest. Although the share of subjects who opted for such answers is low, it should be emphasized that interest is only a general premise of tourism, there may be entities that are not interested in tourism, but who practice it.

The development of coastal tourism presupposes the existence of a tourist potential which, through its attractiveness, is meant to incite and ensure the integration of an area with domestic and international tourist vocation. Therefore, when asked how "the development of coastal tourism positively or negatively influences your activity", $67.6 \%$ of the respondents agree that the activity of their organization is positively influenced by the development of coastal tourism. Coastal tourism can significantly contribute to the achievement of local development objectives, with a significant direct correlation between economic development and income generation and of course, job creation.

A particularly important issue is the advertising of tourist services. To the question "In the area where your organization operates, are there tourist objectives?", $78.9 \%$ of the surveyed respondents answered that there are many resorts, historical, cultural objectives, $21.1 \%$ stating that there are "few". 
Undoubtedly, the Black Sea coastal area is an area with countless historical tourist attractions. Located at the crossroads of two roads, one connecting the North Sea with the Black Sea, crossing central Europe, and the other the ports of the eastern Mediterranean and the Pontic steppes, history has given Dobrogea a troubled fate over the centuries. One by one, several peoples perished: the Persians, Romans, and later, migrant peoples, followed by the Muslim domination/regime. Thus, Dobrogea has been an inhabited territory since ancient times. Archaeological research has revealed countless ancient cities unique in the world: Troesmis, Carsium, Capidava, Histria, Enisala, Argamum, Libida, and so on.

The existence of this wealth, not fully exploited, requires media coverage that must come, first of all, from the human factor, to create a complete tourist product, competitive on the international market. The approach to the issue of advertising was made by asking stakeholders "how do you appreciate the advertising made for these objectives?". Over 70\% of the interviewed entities answered that it is insufficient. It can be observed that the stakeholders involved have the perception of the economic benefit and the socio-cultural impact from the tourism promotion perspective. Stakeholders' motivational aspects of this perception may be related to their divergent views on the Black Sea coastal area.

In this context, it becomes very obvious that the capitalization of tourist resources and the elements of the cultural-historical framework in tourism can generate significant flows of visitors, which can be a crucial aspect that influences the interest of stakeholders.

Regarding the development of coastal tourism, to the question "how is your interest in coastal tourism compared to the period before the COVID-2020 restrictions", 5.6\% of the entities answered that they have an increased interest and at the same time $47.9 \%$ consider that it has remained the same whereas $36.6 \%$ appreciate that interest has decreased for tourism in the Black Sea coastal area. Therefore, it is observed that most stakeholders have a good understanding of the interests of the tourism sector, even in the context of the restrictions imposed by the Covid 19 pandemic which has both desired effects (spending holidays in their own country in greater numbers than usual) and undesirable effects on tourism activities (of course in terms of economic activity, but not only).

When properly developed, maritime spatial planning (MSP) can have significant economic, social, and environmental benefits. In this regard, stakeholders were asked how to assess the quality of environmental issues (such as landscape, air, green areas, noise) and coastal infrastructure (beaches and seaside, hospitality, traffic, restaurants, accommodation, leisure, and entertainment). According to the answers, about $30 \%$ of the respondents consider that the infrastructure of the coastal area is good and very good, while for the quality of the environment about $20 \%$ consider that it is good and very good (Figure no.1). The results of the analysis also indicate that the perceived level has a strong and negative impact on overall satisfaction. Thus, tourism service providers in the Black Sea coastal area should focus on increasing tourist attractiveness so that it increases tourist satisfaction, of course taking into account sustainable economic development and biodiversity conservation. The diversification and intensification of tourist activities in the coastal area can generate pressures on the environment.

An essential role in balancing the demand-supply ratio is played by tourist services, as a dynamizing factor of the entire tourist activity. Tourist services should not be identified only as part of the tourist offer, because they have a decisive influence in determining demand. The quality of the services and their relation with the tariffs practiced decisively influence the tourist movement, being able to constitute a stimulus or a brake. This is why the reliability of services is a vital issue for assessing the quality of services. A tourist service is reliable insofar as it has been provided correctly, of the requested term, according to the destination for which it was designed and offered. 


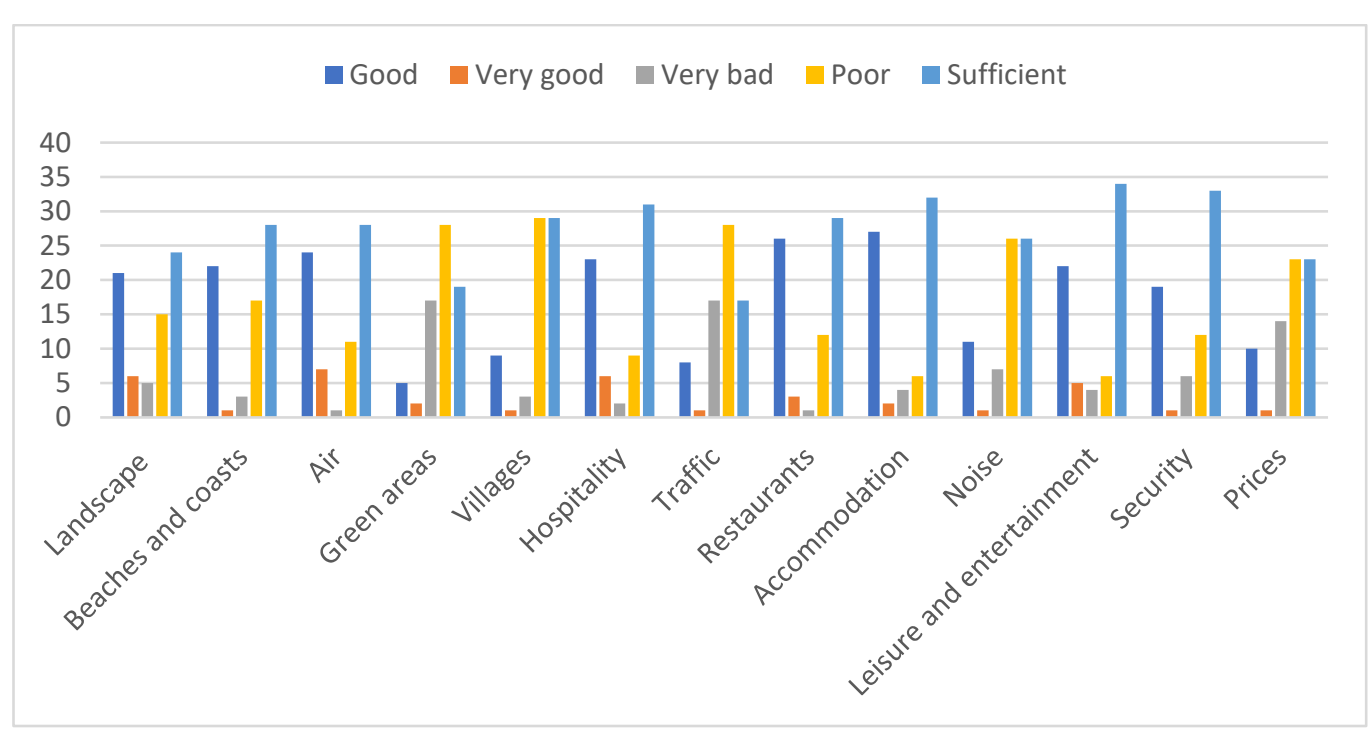

Figure no. 1. Assessment of environmental and coastal infrastructure issues Source: own processing

To the question regarding the evaluation of the quality of some aspects/ services on the Black Sea beach, it is observed that according to the answers, $33 \%$ consider that the seawater is good, $20 \%$ appreciate the cleanliness of the beach whereas $20 \%$ consider the behaviour of those who practice water sports (surfers, jet skiers) good.

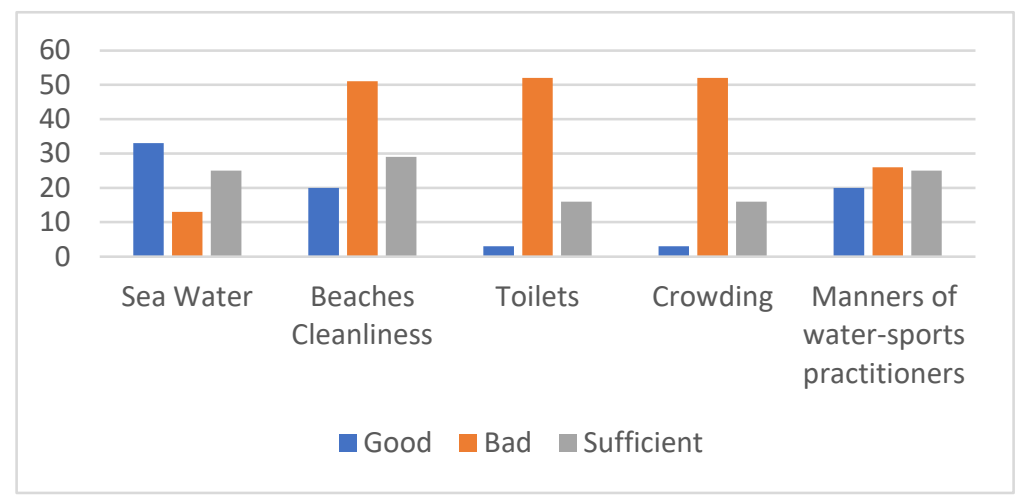

Figure no. 2. Services quality

Source: own processing

The general disagreement on beach cleanliness (51\%), toilets (52\%), and congestion (52\%) should draw the attention of the competent public administration authorities as well as of the economic operators in the tourism field to take the proper measures to improve the degree of tourists' satisfaction.

As seen in Figure no. 2, the main problem of the Romanian coast is the quality of services. Although the questionnaire reported only a few aspects of beach services, the existing problems that directly or indirectly concerned the cleanliness of the beach were due to the existence of pets, street vendors, the insufficient endowment of beaches with showers and exchange cabins, insufficient endowment with beach bars and lifeguard services, the absence of rubbish bins by categories of waste. But this is not the only shortcoming.

The surveyed entities also feel the lack of entertainment activities, excessive congestion, and the uncivilized behaviour of those involved in providing these services. The only element that seems to be appreciated as "good" refers to the quality of seawater. 


\section{Conclusions}

Sustainable local economic development is a complex process, which requires multiple resources, having implications on many aspects of economic, environmental, and social life, trying to establish an optimal balance between them. Identifying the factors involved in maritime spatial planning is an important step in developing a successful strategic plan and taking into account their perceptions of coastal tourism, as an integral part of the maritime spatial planning process is an element that cannot be overlooked. In this sense, two main categories of actors involved in local economic development were outlined. On the one hand, there are those responsible for this process, those who are actively involved in its development, such as local public entities and private entities that implement various development programs. On the other hand, it is about the beneficiaries, those who are affected by the effects of development. This category includes the local community and private entities. Undoubtedly, the most important stakeholder in our research comes from the public sector and is represented by the local public administration. It has the task of getting involved in the economic development of the coastal area, having at hand the multiple possibilities to manage this approach. The obtained results revealed a series of problems related to the quality of services, maintenance, and development of infrastructure and promotion, marketing, all these being recognized as "weaknesses" by most of the interviewed entities.

In conclusion, starting from one of the main characteristics of tourism, namely heterogeneity, and variability, sustainable development in the context of MSP involves different actions in terms of economic, social, and ecological intensity. For each service, the possible adverse effects on the current well-being of the population will be taken into account, as well as those effects that do not negatively influence the life and well-being of future generations.

\section{Acknowledgement}

This work has been supported by the European Commission through the European Maritime and Fisheries Fund, Cross-border Maritime Spatial Planning for Black Sea - Bulgaria and Romania (MARSPLAN-BS-II), EASME/EMFF/2018/1.2.1.5/01/SI2.806725- MARSPLAN-BS-II.

\section{References}

Ashley, C. and Mitchell, J., 2009. Tourism and Poverty Reduction. Pathways to Prosperity. London: Routledge.

Capacci, S., Scorcu, A.E. and Vici, L., 2015. Seaside tourism and eco-labels: The economic impact of Blue Flags. Tourism Management, 47, pp.88-96.

Cavero-Rubio, J.A. and Amorós-Martínez, A., 2020. Environmental certification and Spanish hotels' performance in the 2008 financial crisis. Journal of Sustainable Tourism, 28(5), pp.771-796.

Donázar, J.A., Ceballos, O. and Cortez-Avizanda A., 2018. Tourism in protected areas: Disentangling road and traffic effects on intra-guild scavenging processes. Scienc of The Total Environment, 630, pp.600-608.

Fayissa, B., Nsiah, C. and Tadasse, B., 2008. Impact of Tourism on Economic Growth and Development in Africa. Tourism Economics, 14(4), pp.807-818.

Hall, C.M., 2019. Constructing sustainable tourism development: The 2030 agenda and the managerial ecology of sustainable tourism. Journal of Sustainable Tourism, 27(7), pp.1044-1060.

Hardy, A., S. Beeton, R.J. and Pearson, L., 2002. Sustainable tourism: An overview of the Concept and its Position in Relation to Conceptualisations of Tourism. Journal of Sustainable Tourism, 10(6), pp.475-496.

Hapenciuc, C.V., 2003. Cercetarea statistica în Turism. București: Editura Didactică și Pedagogică.

Holden, A., 2016. Environment and Tourism, Third edition. London: Routledge.

Liu, Z., 2003. Sustainable Tourism Development: A critique. Journal of Sustainable Tourism, 11(6), pp.459-475. 
McKenna, J., Williams, A.T. and Cooper, J.A., 2011. Blue Flag or Red Herring: Do beach awards encourage the public to visit beaches? Tourism Management, 32(3), pp.576-588.

Papageorgiou, M., 2016. Coastal and marine tourism: A challenging factor in Marine Spatial Planning. Ocean \& Coastal Management, 129, pp.44-48.

Sequeira, T.N. and Nunes, P.M., 2008. Does tourism influence economic growth? A dynamic panel data approach. Applied Economics, 40(18), pp.2431-2441.

Supporting maritime spatial Planning in the Easter Mediterranean (SUPREME), 2017. How to perform analysis of land-sea interactions, combining MSP and ICZM in the considered project area, Deliverable No. 1.3.7, [online] Available at: $<$ https://iczmplatform.org/storage/documents/taFUAsAqp9pOnvq8F4zQmNIhMWBTEvocP0qnc F2C.pdf $>$ [Accessed 23 February 2021].

Wang, S.-H., Lee, M.-T., Château, P.-A. and Chang, Y.-C., 2016. Performance Indicator Framework for Evaluation of Sustainable Tourism in the Taiwan Coastal Zone. Sustainability, 8(7), Article number: 652 . 